\title{
Characterisation of mycobacteria isolated from slaughter cattle in
} pastoral regions of Uganda

\author{
$\mathrm{J} \mathrm{Oloya}^{\dagger 1,2}$, R Kazwala ${ }^{\dagger 3}$, A Lund ${ }^{\dagger 4}$, J Opuda-Asibo ${ }^{\dagger 1}$, B Demelash $^{\dagger 5}$, \\ E Skjerve $^{\dagger 2}$, TB Johansen ${ }^{\dagger 4}$ and B Djønne* ${ }^{* \dagger}$
}

Address: ${ }^{1}$ Department of Veterinary Public Health and Preventive Medicine, Makerere University, Kampala, Uganda, ${ }^{2}$ Department of Food Safety and Infection Biology, Norwegian School of Veterinary Science, N-0033, Oslo, Norway, ${ }^{3}$ Sokoine University of Agriculture, Morogoro, Tanzania, ${ }^{4}$ Department of Animal Health, National Veterinary Institute, N-0033 Oslo, Norway and ${ }^{5}$ Department of Veterinary Public Health and Microbiology, University of Hawassa, Awassa, Ethiopia

Email: J Oloya - joloya@vetmed.mak.ac.ug; R Kazwala - kawzr@yahoo.com; A Lund - arve.lund@vetinst.no; J Opuda-Asibo - opudaasibo@vetmed.mak.ac.ug; B Demelash - demelash_b@yahoo.com; E Skjerve - Eystein.Skjerve@veths.no; TB Johansen - tone.bjordaljohansen@vetinst.no; B Djønne* - berit.djonne@vetinst.no

* Corresponding author †Equal contributors

Published: 25 October 2007

BMC Microbiology 2007, 7:95 doi:10.1/86/147/-2180-7-95
Received: 2I March 2007

Accepted: 25 October 2007

This article is available from: http://www.biomedcentral.com/I47I-2/80/7/95

(c) 2007 Oloya et al; licensee BioMed Central Ltd.

This is an Open Access article distributed under the terms of the Creative Commons Attribution License (http://creativecommons.org/licenses/by/2.0), which permits unrestricted use, distribution, and reproduction in any medium, provided the original work is properly cited.

\begin{abstract}
Background: Bovine tuberculosis is a zoonotic problem in pastoral cattle and communities in Uganda. Tuberculin tests in pastoral cattle had shown a high herd but low animal prevalence, with a high proportion of avian reactors. No work had been done to identify the mycobacterial species involved. The objective of the study was to isolate and characterise Mycobacterial species causing tuberculous lesions in slaughtered animals. Lesioned organs compatible with bovine tuberculosis in slaughtered cattle from pastoral areas in Uganda were collected and cultured to isolate mycobacteria. AccuProbe culture identification kits for the Mycobacterium tuberculosis complex, $M$. avium complex and $M$. avium were used to identify the isolates. Spoligotyping and Insertion Sequence (IS) /3 I I and IS / 245 Restriction Fragment Length Polymorphism analysis (RFLP) were used to further characterise the isolates.

Results: Of the $6 \mathrm{I}$ lesioned organs and tissues cultured, 19 isolates were identified as M. bovis, 3 as $M$. avium subsp.hominissuis, I as $M$. intracellulare, I as a mixed culture of $M$. bovis and $M$. avium sp. and $I$ as $M$. avium sp. and unidentified mycobacteria. Eleven other mycobacteria outside the tuberculosis and avium complex groups were also isolated. Ten new spoligopatterns grouped into three clusters were identified from $M$. bovis isolates. Two of the three $M$. avium subsp.hominissuis isolates showed similar patterns on the IS /3 I / RFLP but all were different on the IS / 245 RFLP.

Conclusion: The isolation of $M$. bovis confirms the ongoing infection with spoligotypes unique to Uganda. Isolation of environmental mycobacteria could explain the high avian or non specific tuberculin reactor patterns commonly observed in pastoral cattle and suggests their pathogenic or opportunistic role in the infection of cattle with disseminated bovine tuberculous lesions.
\end{abstract}

\section{Background}

Mycobacterium bovis infections are of major importance in many developed and developing countries, including Uganda [1]. In countries with national bovine tuberculo- 
sis eradication programmes, clinical evidence of tuberculosis in cattle is seldom encountered because the intradermal tuberculin test enables presumptive diagnosis and elimination of infected animals before signs appear [2]. Studies have shown that in the final phases of eradication, strains of Mycobacterium sp. outside the tuberculosis (MOT) complex may increase the relative frequency and cause false positive skin test reactions [3]. In countries without any control programme, including Uganda, clinical symptoms and post mortem lesions associated with bovine tuberculosis (BTB) may still be seen [4].

Post mortem examination followed by bacteriological examination of suspected lesions in cattle are important tools to confirm the presence[5], while molecular studies help to characterise mycobacterial species involved $[6,7]$. Histo-pathological examination may increase the specificity of the diagnosis and in circumstances where the prevalence of bovine tuberculosis is high, pathology can be relied on for diagnosis [5]. However, lesions due to an infection with other mycobacteria can be mistaken for bovine tuberculosis. When the prevalence is low, as in the latter stages of an eradication campaign or under extensive management systems, the need for definitive diagnosis becomes more important and routine culturing of all suspected lesions is recommended.

The combination of conventional methods and molecular typing of isolates have yielded important insights into the epidemiology of tuberculosis in domestic [8-10] and wildlife populations [11-13]. It has permitted a more precise targeting and monitoring efficacy of conventional control measures $[10,14,15]$. It has also provided more precise information on the rate of transmission $[12,16]$, stability of the genetic profiles and has been used in epidemiological tracing [9]. A possible relationship exists between the genotype and phenotype of $M$. bovis and the disease pattern [17]. Different genotypes may differ in pathogenicity and thereby affect the development of lesions and how the animals react to the tuberculin test. This suggests a linkage between immunogenicity with respect to the skin test and possibly transmissibility[17], which traditional approaches to tuberculosis diagnosis could not adequately explain.

Different molecular tools have been developed to differentiate between mycobacterial isolates. Notable are spoligotyping and Restriction Fragment Length Polymorphism (RFLP) based molecular techniques[6]. Spoligotyping is designed to detect the presence or absence of unique spacers within the direct repeat (DR) locus of the M. bovis genome. It is known to distinguish between phenotypically different strains and has been successfully used to type $M$. bovis isolates from different African countries such as Nigeria[18], Chad [19], Cameroon [20], Madagascar
[7] and Tanzania [8]. Spoligotyping has been performed on $M$. bovis isolates obtained from different animals to show the interaction between species. Some spoligotypes have been associated with more sensitivity and specificity to tuberculin, virulence and transmissibility[17].

Different Insertion Sequences (IS)-IS901, IS1311 and IS1245 RFLP have been used to identify and differentiate members outside the tuberculosis complex group [21-25]. IS901 RFLPhas been used to establish the relationship between $M$. avium complex strains isolated from birds, animals, humans, and the environment and virulence for poultry [25]. IS1245 RFLP has low discriminatory power against M.a.subsp.avium but has been very important in the study of epidemiology of M. a. subsp.hominissuis [23]. A closely related IS element is IS1311, which shows 85\% sequence identity with IS1245 at the DNA level [23]. Molecular typing of MOT is important to identify groups previously thought not to play an important role in human and animal infections.

In Uganda, pastoral communities live in close contact with their cattle. The presence of mycobacterial infections in cattle would represent a huge health risk to their owners. Therefore, in endemic areas where bovine and human tuberculosis coexist, the isolation of $M$. bovis from cattle is important in order to prove its presence and thereby elucidate the risk of spreading the infection to humans [26]. There is little information available on agents causing lesions compatible with tuberculosis in slaughtered cattle in Uganda [1], yet recent studies have shown high herd and low animal prevalence of tuberculin reactors in pastoral areas [27]. The high avian or non-specific tuberculin reactor trends encountered in skin tests in pastoral areas made it necessary to provide information on the species of mycobacteria involved.

The aim of the present study was to isolate, identify and characterise mycobacterial species causing pathological lesions compatible with bovine tuberculosis in slaughtered cattle from pastoral areas in Uganda.

\section{Results}

Thirty seven mycobacterial isolates were cultured from 61 samples collected from organs showing lesions compatible with bovine tuberculosis (Table 1). MTC was detected in 20 of the samples; 15 isolates originated from tuberculous lesions (carcase and lung) and five from localised lymph node lesions. Due to the contamination of subcultures, only fifteen $M$. bovis isolates from this study and four additional M. bovis isolates collected from a parallel field study in cattle in the same areas were examined by spoligotyping, ten distinct spoligo patterns were identified. They were grouped into three clusters of $>95 \%$ similarity (Figure 1). All isolates lacked spacers 3, 9, 16 and 
Table I: Mycobacteria isolated from 6I tuberculous lesions in pastoral slaughtered cattle in Uganda

\begin{tabular}{lll}
\hline Mycobacterial species & Number & Percent \\
\hline M. bovis & 19 & 51.4 \\
M. avium subsp . hominissuis & 3 & 8.1 \\
M. intracellulare & $\mathrm{I}$ & 2.7 \\
M. avium sp. & $\mathrm{I}$ & 2.7 \\
M. bovis + M. avium sp. & $\mathrm{I}$ & 2.7 \\
M. avium sp. + unidentified mycobacteria & $\mathrm{I}$ & 2.7 \\
Unidentified mycobacteria & $\mathrm{II}$ & 29.7 \\
Total & 37 & 100.0 \\
\hline
\end{tabular}

39-43 as most $M$. bovis isolates do and they also lacked spacers 6 and 7 . In addition, members of the first cluster (B-1, B-2, B-3, B-4 and B-5) lacked spacers 1 and 36. They showed slight variations, as B-1 lacked spacer 4, B-2 and B-3 lacked spacer 15 and B4 lacked spacer 32. All members of the second cluster lacked spacers 4 and 5, all except one (B-19) lacked spacer 15 and B-6 lacked spacer 10 . The nine members of the third cluster lacked spacers 4, 5 and 18-22. In addition B-7, B-8, B-9, B-10, B-11, B-12 and B13 lacked spacers 15 , while B-7 also lacked spacers 13 and 14. The samples were too few to establish any association between the spoligotypes and nature of the lesions they were isolated from.

MOT were detected in 18 samples. Of these, one isolate was identified on MAC and M. avium accuprobes as $M$. intracellulare and two others as $M$. avium sp. Most of the unidentified mycobacteria (10 out of 11) were isolated from disseminated tuberculous lesions and only one was from a local lymph node (lateral retropharyngeal). The two cases of mixed infections were isolated from disseminated tuberculosis lesions. Of the three M. avium sp. examined by IS1245 and IS1311 RFLP, two showed four bands on the IS1311 RFLP while the last isolate showed 8 bands. All three isolates showed different patterns with 13 or 14 bands on IS1245 RFLP and were identified as M. avium subsp. hominissuis [22,28] (Figure 2).

\section{Discussion}

Different mycobacterial species were isolated in lesions compatible with bovine tuberculosis in pastoral slaughtered cattle in Uganda. M. bovis was found in $51.4 \%$ and mycobacteria outside the M. tuberculosis complex (MOT) in $48.6 \%$ of the 37 samples where mycobacteria were detected. These results were comparable to the $42 \%$ isolation rate of $M$. bovis in mycobacteria positive cultures in Chad [19]. This is the first study in Uganda to document that other mycobacterial species are involved in cattle infections and also reports the spoligotypes of $M$. bovis involved. Earlier identification studies were mainly based on colonial and biochemical characteristics [1].

Many thousands of cattle were examined during the nine month study period, still only 61 animals with macroscopic lesions compatible with bovine tuberculosis were detected. The low number of lesioned animals reflect the low prevalence of BTB in Uganda [27] and probably also the low sensitivity of post mortem examinations $[1,5]$. However, the isolation of $M$. bovis from slaughtered cattle confirms that bovine tuberculosis is present in pastoral
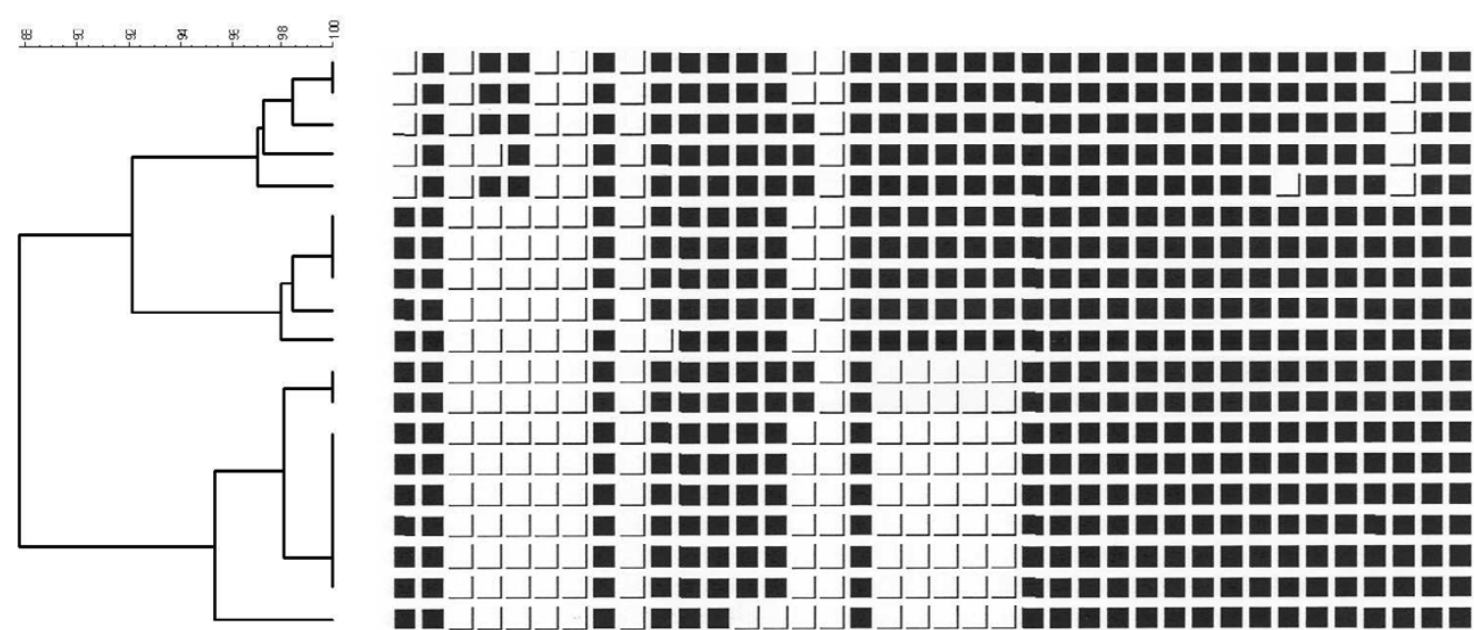

Figure I

Spoligotypes of $M$. bovis isolated from slaughtered cattle in Uganda. Lack of spacers 39-43 is not shown in the figure. 
IS1311 RFLP

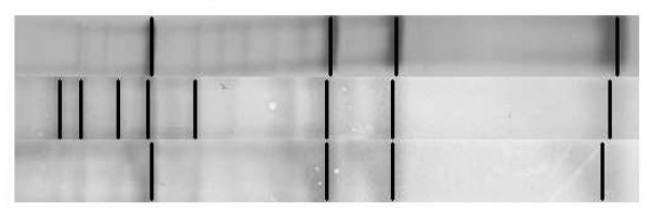

IS1245 RFLP

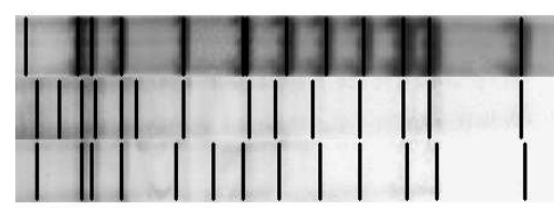

Isolate number

B-1

B-2

B-3

Figure 2

The IS I 3 I I and I 245 RFLP patterns of M. avium sp hominissuis.

areas in the cattle corridor of mid-central and mid-western regions of Uganda. As documented elsewhere in Africa [29], pastoralists in Africa in general have an obsessive attachment to their cattle. Their diet mostly of raw milk, fresh blood and occasionally meat could be regarded as potential sources of infection [30]. The isolation of $M$. bovis from their cattle should be considered a serious public health concern [31]. In endemic areas where bovine and human tuberculosis coexist, the documentation of the existing strains of $M$. bovis is important for monitoring the spread of $M$. bovis among cattle and between cattle and humans [26]. Two of the M. bovis spoligotypes (B-6 and B13) isolated from slaughtered cattle were also isolated from 3 human cases of cervical lymphadenitis, in a parallel study in humans, though from different locations [32]. This documents an existing infection from cattle to humans and further highlights the potential threat of BTB to humans in rural communities [26,33-35].

Owing to the difficulties encountered in tracking the origin of these cattle, it was not possible to link them to any specific geographic area. However, spoligotypes found in other African countries $[7,8,18,20]$ were not detected in Uganda. Comparison of the Ugandan spoligotypes with the $M$. bovis database [49] and tuberculosis database SpolDB4 [36] showed that these particular spoligotypes were unique and not documented elsewhere.

Isolation of M. avium subsp. hominissuis and other MOT in cattle with disseminated tuberculosis lesions could signify the importance of these bacteria in pastoral communities and their cattle. M. avium sp. hominissuis and other environmental mycobacteria have been isolated from swine, cattle, sheep, goats and horses [25,37], wild and domestic birds [3] and humans [38-40]. In contrast to M. avium subsp. avium infections in wild and domestic birds, these infections in mammals occur only sporadically and are rarely transmissible [3]. Generalised disease due to MOT is usually uncommon, owing to the non-progressive, chronic character of the infection. However, some cases of disseminated disease have been reported, especially in captive non-domestic hoofed animals and pigs [41]. The relatively high rate of isolation of MOT $(48.6 \%)$ in the current study (Table 1), calls for special attention. The isolation of mycobacteria mostly considered opportunistic or less virulent $[3,42]$ in conditions of disseminated tuberculosis with fully caseated and calcified lesions is documented elsewhere[3]. However, mixed infections, as documented in other studies [43], were observed in caseated and/or calcified disseminated lesions in this study. These findings could suggest secondary mycobacterial infections or may have outgrown the slow growing $M$. bovis during culture[3]. Isolation of MOT in this study is consistent with earlier findings in pastoral areas, in which high avian and doubtful reactor trends were reported [27]. Sensitisation of test animals with environmental mycobacteria have been documented as interfering with the interpretation of tuberculin results by affecting sensitivity and specificity [44].

Many mycobacterial species are ubiquitous organisms in environmental reservoirs; especially in water and soil $[3,42,45-47]$ and can survive and multiply under a wide range of environmental conditions. Their recovery from tissues of slaughter animals originating from such areas is indicative of the mycobacterial status of the environment and water sources $[3,45,46]$ as well as their potential to cause infection [3]. In most pastoral areas in Uganda, animals drink from natural water holes, dug out ponds or valley dams or tanks, which are often heavily contaminated with animal waste. As documented, water high in organic matter or animal dejections enhances the growth of environmental mycobacteria [3] and such water constitutes the greatest risk of exposure to humans and animals $[42,48]$.

\section{Conclusion}

This study confirmed the presence of $M$. bovis among cattle in the pastoral cattle corridor in mid-central and midwestern areas of Uganda and detected new and specific 
spoligotypes not reported before. Furthermore, the study gives an insight into other mycobacterial species infecting cattle in this region and thereby contributes to explaining the high avian or non specific reactor patterns commonly observed in tuberculin tested animals in these areas. Strong avian reactions in the tuberculin testing scheme reduce the tuberculin test specificity, something that calls for a review of the interpretation of tuberculin tests in pastoral areas.

\section{Methods \\ Collection of samples}

The samples were collected from slaughtered cattle originating from pastoral areas in the cattle corridors of Nakasongola, Luwero, Masindi and Mbarara districts brought to Kalerwe Abattoir, North of Kampala during a nine month period between 2004 and 2005. It was not possible to trace the place of origin of the animals, due to poor documentation, cattle markets with large overlapping catchment areas spanning many districts and the crisscrossing nature of rural transportation of animals and traders withholding information due to the illegal movement of cattle in areas under quarantine. Tissue samples from 61 cattle showing macroscopic lesions compatible with bovine tuberculosis during the post mortem examination were collected and submitted to the laboratory for processing and storage at $-70^{\circ} \mathrm{C}$.

\section{Tissue Preparation and Culture}

Fat and connective tissue were removed from the specimens and approximately $10 \mathrm{~g}$ were placed in sterile stomacher bags containing $30 \mathrm{ml}$ of physiological buffered saline and homogenised in the stomacher machine for 7 10 minutes. The homogenate was transferred into tubes and an equal volume of Sodium hydroxide-N-acetyl-Lcysteine (NaOH-NALC) decontamination solution [containing $6.8 \%$ Sodium Hydroxide $(\mathrm{NaOH}), 2.9 \%$ sodium citrate and $0.5 \% \mathrm{~N}$-acetyl-L-cysteine (NALC) to a final concentration of $1.7 \% \mathrm{NaOH}$ ] was added. After vortexing, the specimens were left at room temperature for $15 \mathrm{~min}$. Subsequently $5 \mathrm{ml}$ of sterile $0.067 \mathrm{M}$ phosphate buffer (pH 6.8) was added and the mixture was centrifuged at $3660 \times \mathrm{g}$ for $15 \mathrm{~min}$. The supernatant was discarded and the sediment was inoculated on Lowenstein-Jensen (Difco Laboratories, Detroit, Michigan) media with and without pyruvate $(0.6 \%)$ and incubated at $37^{\circ} \mathrm{C}$. Tubes were read weekly for up to 12 weeks. Of the 61 lesioned specimens collected and cultured, 37 grew mycobacteria. Four additional mycobacterial isolates were obtained from apparently normal lymph nodes from a parallel study in the same area. Typical or suspect colonies were harvested into cryotubes containing $1.5 \mathrm{ml}$ Middlebrook 7H9 (Difco Laboratories, Detroit, MI) and stored at $-70^{\circ} \mathrm{C}$ at the National Tuberculosis Referral Laboratory, Uganda. The isolates were transported to the National Veterinary
Institute, Oslo and sub cultured on Middlebrook 7H10 and Stonebrink media (Difco Laboratories, Detroit, MI).

\section{Identification of mycobacterial isolates}

All acid fast bacteria, determined by the Ziehl-Neelsen (ZN) staining technique, were examined by the AccuProbe MTC (mycobacterium tuberculosis complex) identification kit (GEN-PROBE ${ }^{\circledR}$ INC. San Diego, California) as described by the producer. Results were considered positive when Relative Light Units (RLU) were greater than 30 000, repeat range; $20000-29000$ and negative; below 20 000. Samples negative on the MTC kit were examined further on the AccuProbe MAC (M. avium complex) and AccuProbe $M$. avium culture identification kits. Final results were interpreted as follows; cultures positive on the M. avium and MAC culture identification kits were considered $M$. avium species and cultures negative on the $M$. avium kit and positive on the MAC kit were identified as M. intracellulare. Samples negative on all AccuProbe culture identification kits were grouped as unidentified $m y c o-$ bacteria.

\section{Spoligotyping and Analysis of the spoligotyping patterns}

Cultures belonging to the $M$. tuberculosis complex were submitted for further differentiation by Spoligotyping [20] as described by the producer (Isogen, Life science, The Netherlands). DNA was isolated using theQuiagen DNA extraction Kit for cell cultures (Qiagen ${ }^{\mathrm{TM}}$, Nordic) following the manufacturer's instruction manual, PCR and hybridisation were performed as described [21]. The amplified DNA was hybridised to a membrane containing 43 oligonucleotides in a miniblotter (MN45, Immunetics, Cambridge, Massachusetts). Bound fragments were revealed by chemiluminescence after incubation with horseradish peroxidase-streptavidin (Boehringer, Mannheim, Germany) for $45 \mathrm{~min}$ at $45^{\circ} \mathrm{C}$ and the membrane was exposed to X-ray film (Hyperfilm, Amersham) for 1012 min. The M. tuberculosis H37Rv and M. bovis BCG were included as controls.

The results were analysed using the BioNumerics programme version3.5(Applied Maths, Kortrijk, Belgium). Normalisation of the fingerprints was done using the molecular weight standard $1 \mathrm{~kb}$ DNALadder (Invitrogen ${ }^{\mathrm{TM}}$, Carlsbad, Calif.). The BioNumerics software was used to calculate Dice coefficients of similarity and to cluster the isolates and generate dendograms by the unweighted-pair group method using linkage averages. The optimisation and tolerance settings were both set at $2.00 \%$.

\section{Examination by IS I 3 I I and IS I 245 RFLP}

Cultures identified as M. avium sp. were further examined using IS1245 and IS1311 Restriction Fragment Length Polymorphism (RFLP). The DNA extraction, RFLP analysis and interpretation of results were performed as previ- 
ously described [22], using the described probes for IS1245 and IS1311 RFLP.

\section{Competing interests}

The author(s) declares that there are no competing interests.

\section{Authors' contributions}

JO: Principal investigator, participated in the conception and design of the study, general conduct of the study, acquisition of data, isolation and culture of mycobacteria, molecular studies and drafted manuscript. R.K: Conception and design of the study, general conduct of the study, acquisition of data, isolation and culture of mycobacteria. $\mathrm{AL}$ : Participated in the conception and design of the study, acquisition of funding, general conduct of the study, isolation and culture of mycobacteria and critical revision of the manuscript for important intellectual content. J.O-A: Participated in the conception and design of the study, general supervision of the research group in Uganda. General conduct of the study, acquisition of data, isolation and culture of mycobacteria, molecular studies and critical revision of the manuscript for important intellectual content. ES:Acquisition of funding, general supervision of the research group in Norway, participated in the conception and design of the study, acquisition of data, drafted the manuscript. B.D: Participated in the design of the study, general supervision of the laboratoty work in Norway, isolation and culture, molecular studies and critical revision of the manuscript for important intellectual content. TBJ: Carried out the molecular genetic studies, participated in the sequence alignment and drafted the manuscript. BD:Isolation and culture, molecular genetic studies and critical revision of the manuscript for important intellectual content.

All the authors have read and approved the final version of the manuscript.

\section{Acknowledgements}

We are grateful to the Norwegian Council for Higher Education (NUFU), Norway for funding the project through the North-South Collaboration between the Norwegian School of Veterinary Science and Makerere University. Also, special thanks go to Vivi Myran and Merete Jensen, National Veterinary Institute in Norway, Dr. Francis Adatu-Engwau, Director and Mr. Elisha Hatanga, Supervisor of the Wandegeya National Tuberculosis and Leprosy Programme (NTLP) Laboratory, Kampala-Uganda for their permission and the technical advice they provided.

\section{References}

I. Acen F: Pre and Post-slaughter diagnosis of tuberculosis in cattle in Kampla abattoir-Uganda. In Msc Thesis Monograph Makerere University; 1991.

2. Phillips CJ, Foster CR, Morris PA, Teverson R: The transmission of Mycobacterium bovis infection to cattle. Res Vet Sci 2003, 74(I): $1-15$.

3. Biet F, Boschiroli ML, Thorel MF, Guilloteau LA: Zoonotic aspects of Mycobacterium bovis and Mycobacterium avium-intracellulare complex (MAC). Vet Res 2005, 36(3):4I I-436.
4. WHO/FAO/OIE: Report on Consultation on Animal Tuberculosis Vaccines. WHO. Geneva: Veterinary Public Health Unit; $200 \mathrm{I}$.

5. Corner LA: Post mortem diagnosis of Mycobacterium bovis infection in cattle. Vet Microbiol I994, 40(I-2):53-63.

6. Haddad N, Masselot M, Durand B: Molecular differentiation of Mycobacterium bovis isolates. Review of main techniques and applications. ResVetSci 2004, 76(I): I- I8.

7. Rasolofo Razanamparany V, Quirin R, Rapaoliarijaona A, Rakotoaritahina $\mathrm{H}$, Vololonirina EJ, Rasolonavalona T, Ferdinand S, Sola C, Rastogi $\mathrm{N}$, Ramarokoto $\mathrm{H}$, Chanteau S: Usefulness of restriction fragment length polymorphism and spoligotyping for epidemiological studies of Mycobacterium bovis in Madagascar: description of new genotypes. Vet Microbiol 2006, I I 4: I I5-22.

8. Kazwala RR, Kusiluka LJ, Sinclair K, Sharp JM, Daborn CJ: The molecular epidemiology of Mycobacterium bovis infections in Tanzania. Vet Microbiol 2006, I I 2(2-4):201-2I0.

9. Perumaalla VS, Adams LG, Payeur J, Baca D, Ficht TA: Molecular fingerprinting confirms extensive cow-to-cow intra-herd transmission of a single Mycobacterium bovis strain. Vet Microbiol 1999, 70(3-4):269-276.

10. Skuce RA, Neill SD: Molecular epidemiology of Mycobacterium bovis: exploiting molecular data. Tuberculosis (Edinburgh, Scotland) 200I, 8 I (I-2):169-175.

II. Hermoso de Mendoza J, Parra A, Tato A, Alonso JM, Rey JM, Pena J, Garcia-Sanchez A, Larrasa J, Teixido J, Manzano G, Cerrato R, Pereira G, Fernandez-Llario P, Hermoso de Mendoza M: Bovine tuberculosis in wild boar (Sus scrofa), red deer (Cervus elaphus) and cattle (Bos taurus) in a Mediterranean ecosystem (1992-2004). Prev Vet Med 2006, 74(2-3):239-47.

12. Parra A, Fernandez-Llario P, Tato A, Larrasa J, Garcia A, Alonso JM, Hermoso de Mendoza M, Hermoso de Mendoza J: Epidemiology of Mycobacterium bovis infections of pigs and wild boars using a molecular approach. Vet Microbiol 2003, 97(I-2): I 23-I33.

13. Parra A, Garcia A, Inglis NF, Tato A, Alonso JM, Hermoso de Mendoza M, Hermoso de Mendoza J, Larrasa J: An epidemiological evaluation of Mycobacterium bovis infections in wild game animals of the Spanish Mediterranean ecosystem. Res Vet Sci 2006, 80(2): I 40-I 46.

14. Aranaz A, Liebana E, Mateos A, Dominguez L, Cousins D: Restriction fragment length polymorphism and spacer oligonucleotide typing: a comparative analysis of fingerprinting strategies for Mycobacterium bovis. Vet Microbiol 1998, 6I(4):3II-324.

15. Van Soolingen D: Molecular epidemiology of tuberculosis and other mycobacterial infections: main methodologies and achievements. J Intern Med 200I, 249(I):I-26.

16. Parra A, Larrasa J, Garcia A, Alonso JM, de Mendoza JH: Molecular epidemiology of bovine tuberculosis in wild animals in Spain: a first approach to risk factor analysis. Vet Microbiol 2005, I I 0(3-4):293-300.

17. Goodchild AV, De la Rua-Domenech R, Palmer S, Dale J, Gordon SV, Hewinson RG, Clifton-Hardley RS: Association between molecular type and epidemiological features of Mycobacterium bovis in cattle. In The Society for Veterinary Epidemiology and Preventive Medicine: 2003 University of Warwick: The Society for Veterinary Epidemiology and Preventive Medicine; 2003:45-59.

18. Cadmus S, Palmer S, Okker M, Dale J, Gover K, Smith N, Jahans K, Hewinson RG, Gordon SV: Molecular analysis of human and bovine tubercle bacilli from a local setting in Nigeria. J Clin Microbiol 2006, 44(I):29-34.

19. Diguimbaye-Djaibe C, Hilty M, Ngandolo R, Mahamat HH, Pfyffer GE, Baggi F, Hewinson G, Tanner M, Zinsstag J, Schelling E: Mycobacterium bovis isolates from tuberculous lesions in Chadian zebu carcasses. Emerg Infect Dis 2006, I 2(5):769-77I.

20. Njanpop-Lafourcade BM, Inwald J, Ostyn A, Durand B, Hughes S, Thorel MF, Hewinson G, Haddad N: Molecular typing of Mycobacterium bovis isolates from Cameroon. J Clin Microbiol 200I, 39(I):222-227.

21. Bartos M, Hlozek P, Svastova P, Dvorska L, Bull T, Matlova L, Parmova I, Kuhn I, Stubbs J, Moravkova M, Kintr J, Beran V, Melicharek I, Ocepek M, Pavlik I: Identification of members of Mycobacterium avium species by Accu-Probes, serotyping, and single IS900, IS90I, ISI 245 and IS90I-flanking region PCR with internal standards. J Microbiol Methods 2006, 64(3):333-45.

22. Dvorska L, Bartos M, Ostadal O, Kaustova J, Matlova L, Pavlik I: $I S I 3 I I$ and ISI 245 restriction fragment length polymorphism 
analyses, serotypes, and drug susceptibilities of Mycobacterium avium complex isolates obtained from a human immunodeficiency virus-negative patient. J Clin Microbiol 2002, 40(10):37|2-37|9.

23. Johansen TB, Olsen I, Jensen MR, Dahle UR, Holstad G, Djonne B: New probes used for ISI 245 and ISI3III restriction fragment length polymorphism of Mycobacterium avium subsp. avium and Mycobacterium avium subsp. hominissuis isolates of human and animal origin in Norway. BMC Microbiol 2007, 7:14.

24. Machackova-Kopecna M, Bartos M, Straka M, Ludvik V, Svastova P, Alvarez J, Lamka J, Trcka I, Treml F, Parmova I, Pavlik I: Paratuberculosis and avian tuberculosis infections in one red deer farm studied by IS900 and IS90I RFLP analysis. Vet Microbiol 2005, 105(3-4):26I-8.

25. Pavlik I, Svastova P, Bartl J, Dvorska L, Rychlik I: Relationship between IS90I in the Mycobacterium avium complex strains isolated from birds, animals, humans, and the environment and virulence for poultry. Clin Diagn Lab Immunol 2000, 7(2):2।2-2।7.

26. Leite CQ, Anno IS, Leite SR, Roxo E, Morlock GP, Cooksey RC: Isolation and identification of mycobacteria from livestock specimens and milk obtained in Brazil. Mem Inst Oswaldo Cruz 2003, 98(3):319-323.

27. Oloya J, Opuda-Asibo J, Djonne B, Muma JB, Matope G, Kazwala R, Skjerve E: Responses to tuberculin among Zebu cattle in the transhumance regions of Karamoja and Nakasongola district of Uganda. Trop Anim Health Prod 2006, 38(4):275-283.

28. Mijs W, de Haas P, Rossau R, Van der Laan T, Rigouts L, Portaels F, van Soolingen D: Molecular evidence to support a proposal to reserve the designation Mycobacterium avium subsp. avium for bird-type isolates and ' $M$. avium subsp. hominissuis' for the human/porcine type of $\mathbf{M}$. avium. Int J Syst Evol Microbiol 2002, 52(Pt 5): $1505-1518$.

29. Cosivi O, Grange JM, Daborn CJ, Raviglione MC, Fujikura T, Cousins D, Robinson RA, Huchzermeyer HF, de Kantor I, Meslin FX: Zoonotic tuberculosis due to Mycobacterium bovis in developing countries. Emerg Infect Dis 1998, 4(I):59-70.

30. Cleaveland S, Shaw DJ, Mfinanga SG, Shirima G, Kazwala RR, Eblate E, Sharp M: Mycobacterium bovis in rural Tanzania: risk factors for infection in human and cattle populations. Tuberculosis (Edinburgh, Scotland) 2007, 87(I):30-43.

31. Gibson AL, Hewinson G, Goodchild T, Watt B, Story A, Inwald I, Drobniewski FA: Molecular epidemiology of disease due to Mycobacterium bovis in humans in the United Kingdom. J Clin Microbiol 2004, 42(I):43I-434.

32. Oloya J, Opuda-Asibo J, Kazwala R, Demelash AB, Skjerve E, Lund A, Johansen TB, Djonne B: Mycobacteria causing human cervical lymphadenitis in pastoral communities in the Karamoja region of Uganda. Epidemiol Infect 2007: I-8.

33. Kazwala RR, Daborn CJ, Sharp JM, Kambarage DM, Jiwa SF, Mbembati NA: Isolation of Mycobacterium bovis from human cases of cervical adenitis in Tanzania: a cause for concern? Int J Tuberc Lung Dis 200I, 5(I):87-91.

34. Mfinanga SG, Morkve O, Kazwala RR, Cleaveland S, Sharp MJ, Kunda J, Nilsen R: Mycobacterial adenitis: role of Mycobacterium bovis, non-tuberculous mycobacteria, HIV infection, and risk factors in Arusha, Tanzania. East Afr Med J 2004, 8 I (4): I 7 I- 178.

35. Thoen C, Lobue P, de Kantor I: The importance of Mycobacterium bovis as a zoonosis. Vet Microbiol 2006, I I 2(2-4):339-345.

36. Brudey K, Driscoll JR, Rigouts L, Prodinger WM, Gori A, AI-Hajoj SA, Allix C, Aristimuno L, Arora J, Baumanis V, Binder L, Cafrune P, Cataldi A, Cheong S, Diel R, Ellermeier C, Evans JT, Fauville-Dufaux M, Ferdinand S, Garcia de Viedma D, Garzelli C, Gazzola L, Gomes HM, Guttierez MC, Hawkey PM, van Helden PD, Kadival GV, Kreiswirth BN, Kremer K, Kubin M, Kulkarni SP, Liens B, Lillebaek T, Ho ML, Martin C, Martin C, Mokrousov I, Narvskaia O, Ngeow YF, Naumann L, Niemann S, Parwati I, Rahim Z, Rasolofo-Razanamparany V, Rasolonavalona T, Rossetti ML, Rusch-Gerdes S, Sajduda A, Samper S, Shemyakin IG, Singh UB, Somoskovi A, Skuce RA, van Soolingen D, Streicher EM, Suffys PN, Tortoli E, Tracevska T, Vincent V, Victor TC, Warren RM, Yap SF, Zaman K, Portaels F, Rastogi N, Sola C: Mycobacterium tuberculosis complex genetic diversity: mining the fourth international spoligotyping database (SpolDB4) for classification, population genetics and epidemiology. $B M C$ Microbiol 2006, 6:23.
37. Matlova L, Dvorska L, Ayele WY, Bartos M, Amemori T, Pavlik I: Distribution of Mycobacterium avium complex isolates in tissue samples of pigs fed peat naturally contaminated with mycobacteria as a supplement. / Clin Microbiol 2005, 43(3): | 26|- 268.

38. Nigg AP, Sternfeld T, Gamarra F, Krotz M, Belohradsky BH, Bogner JR: Recurring disseminated Mycobacterium avium infections in an HIV-negative patient. Dtsch Med Wochenschr 2005, I30(22): | 369-| 372.

39. Primm TP, Lucero CA, Falkinham JO 3rd: Health impacts of environmental mycobacteria. Clin Microbiol Rev 2004, I 7(I):98-106.

40. von Reyn CF, Arbeit RD, Horsburgh CR, Ristola MA, Waddell RD, Tvaroha SM, Samore M, Hirschhorn LR, Lumio J, Lein AD, et al.: Sources of disseminated Mycobacterium avium infection in AIDS. J Infect 2002, 44(3): I66-170.

4I. Thorel MF, Huchzermeyer HF, Michel AL: Mycobacterium avium and Mycobacterium intracellulare infection in mammals. Rev Sci Tech 200I, 20(I):204-2I8.

42. Falkinham JO 3rd: Nontuberculous mycobacteria in the environment. Clin Chest Med 2002, 23(3):529-55I.

43. Godfroid J, Delcorps C, Irenge LM, Walravens K, Marche S, Gala JL: Definitive differentiation between single and mixed mycobacterial infections in red deer (Cervus elaphus) by a combination of duplex amplification of p34 and $f 57$ sequences and Hpy 188 I enzymatic restriction of duplex amplicons. J Clin Microbiol 2005, 43(9):4640-4648.

44. Cooney R, Kadza J, Quinn J, Cook B, Muller K, Monaghan M: Environmental mycobacteria in Ireland as a source of non-specific sensitization to tuberculins. IrVet] 1997, 50:370-373.

45. Dailloux M, Laurain C, Weber M, Hartemann P: Water and nontuberculous mycobacteria. Water Res 1999, 33:2219-2228.

46. livanainen E, Martikainen PJ, Vaananen P, Katila ML: Environmental factors affecting the occurrence of mycobacteria in brook sediments. J Appl Microbiol 1999, 86(4):673-68I.

47. Kirschner RA, Parker BC, Falkinham JO: Humic and fulvic acids stimulate the growth of Mycobacterium avium. FEMS Microbiol Ecol 1999, 30(4):327-332.

48. Falkinham $\mathrm{JO}$ 3rd: Epidemiology of infection by nontuberculous mycobacteria. Clin Microbiol Rev 1996, 9(2):177-215.

49. Mycobacterium bovis Spoligotype Database [http://www.mbo vis.org]
Publish with Biomed Central and every scientist can read your work free of charge

"BioMed Central will be the most significant development for disseminating the results of biomedical research in our lifetime. "

Sir Paul Nurse, Cancer Research UK

Your research papers will be:

- available free of charge to the entire biomedical community

- peer reviewed and published immediately upon acceptance

- cited in PubMed and archived on PubMed Central

- yours - you keep the copyright
BioMedcentral 